\title{
Ride in Peace: How Cycling Infrastructure Types Affect Traffic Conflict Occurrence in Montréal, Canada
}

\author{
Vincent Jarry (D) and Philippe Apparicio *(D) \\ Centre Urbanisation Culture Société, Institut National de la Recherche Scientifique (INRS), 385 Sherbrooke E, \\ Montréal, QC H2X 1E3, Canada; vincent.jarry@inrs.ca \\ * Correspondence: philippe.apparicio@inrs.ca
}

Citation: Jarry, V.; Apparicio, P. Ride in Peace: How Cycling Infrastructure Types Affect Traffic Conflict Occurrence in Montréal, Canada. Safety 2021, 7, 63. https://doi.org/ 10.3390 /safety7030063

Academic Editor: Raphael Grzebieta

Received: 22 April 2021

Accepted: 7 September 2021

Published: 9 September 2021

Publisher's Note: MDPI stays neutral with regard to jurisdictional claims in published maps and institutional affiliations.

Copyright: (c) 2021 by the authors. Licensee MDPI, Basel, Switzerland. This article is an open access article distributed under the terms and conditions of the Creative Commons Attribution (CC BY) license (https:/ / creativecommons.org/licenses/by/ $4.0 /)$.

\begin{abstract}
Urban cycling is increasingly common in many North American cities and has the potential to address key challenges of urban mobility, congestion, air pollution and health. However, lack of safety is often cited by potential bike users as the most important deterrent to cycling. This study aimed to evaluate the effect of cycling facility type on traffic conflict likelihood. Four participants recorded a total of $87 \mathrm{~h}(1199 \mathrm{~km})$ of video, which was reviewed by trained observers to identify and characterize traffic conflicts, yielding 465 conflicts with vehicles and 209 conflicts with pedestrians. Bootstrapped generalized additive logit regressions (GAM) were built to predict traffic conflict likelihood. Results show that while cycling on an off-street bike path effectively reduces the likelihood of conflict with a vehicle, it increases the probability of conflict with a pedestrian. Bike lanes were associated with an increase in the likelihood of a conflict with a vehicle. Decision makers should favor physically segregated and clearly marked cyclist-only facilities to ensure safe and efficient conditions for commuter cyclists.
\end{abstract}

Keywords: traffic conflicts; quasinaturalistic cycling study; cycleways; cycling facilities; cycling safety; generalized additive model (GAM)

\section{Introduction}

While improving their individual health and reducing traffic and pollution, urban cyclists are vulnerable to many risks, such as air pollution and noise exposure, as well as injuries from collisions with other road users [1-6]. In the midst of an "urban cycling renaissance" in many North American cities, great attention is dedicated to improving cycling conditions [7]. Lack of safety is one of the most common deterrents identified by potential bicycle users [8]. Usual methods to evaluate safety include police-declared collisions and hospital admissions databases [9]. However, these studies often suffer from underreporting bias since most minor injuries and crashes are not reported to authorities [10].

Surrogate safety measures were developed to counteract the limitations inherent to crash and injury study designs. With traffic conflict analysis, it is possible to study interactions between road users and characterize them as normal or conflictual [11]. Conflicts are conceptually close to collisions: they are defined as "an interaction between a bicyclist and another road user such that at least one of the parties has to change speed or direction to avoid a collision" [9] (p. 4). Studying conflicts is proactive rather than reactive, meaning that it does not rely on a crash to actually happen in order to conduct the research [11]. Furthermore, noncollision safety events (conflicts), ranging from right-of-way encroachments to near-miss experiences, are known to play an important role in cycling motivation and perceived traffic risk [12-14], sometimes even more than collisions, since the former are far more frequent than the latter. Though traffic conflict analysis was mostly developed for car driving studies since the 1970s, its use to study cyclist interactions is increasing [15].

Methods to study traffic conflicts include fixed-site observation [11,15-17] and naturalistic cycling studies using instrumented bicycles [18-22]. Fixed-site observation with a video camera offers an omniscient view on the interactions between the road users, thus 
allowing researchers to compute many traffic conflict indicators, such as postencroachment time (PET) and time-to-collision (TTC) $[11,15,16]$. On the other hand, naturalistic cycling studies (or more generally, mobile data collections) offer the potential to cover a broad territory and a wide variety of urban contexts $[18,23]$.

\subsection{Cycling Risk and Protection Factors}

Factors influencing cycling safety are both individual and contextual. Individual factors are those specific to every cyclist. Some studies have shown that male cyclists are less likely to experience conflicts and collisions than their female counterparts are [11,24]. Level of cycling experience may also play a role in the ability to maneuver in complex cycling conditions $[11,21]$. Older cyclists and cyclists that do not wear reflective clothing are more likely to experience severe injury or fatality [25]. When approaching at a higher speed, a cyclist risks experiencing a more severe conflict than when riding at a lower speed [11].

Contextual factors apply to every cyclist in a given environment. For example, in Valencia, it was found that bus stops were pedestrian conflict hotspots along a protected cycle track corridor (passengers either crossing the cycle track to enter or exit the bus or standing in the cycle track waiting for the next departure) [26]. Riding on a slope can lead to an increase in crash or conflict occurrence and severity [9,27-29]. Time of day, day of the week and geographical position can also affect traffic risks for cyclists since traffic conditions vary greatly across time $[21,22,27,28]$ and space $[22,30,31]$. Intersections are natural conflict and collision hotspots $[18,21-23,27-29]$. Uneven or poorly maintained road surfaces can lead to crashes and conflicts $[22,23,27,32]$.

Among contextual factors, those concerning the built environment, and more specifically, cycling facility type, are those upon which urban planners have the greatest leverage. It is generally accepted that bicycle-specific infrastructure has a protective effect on cyclists' safety $[9,21-23,27,28,33]$. For example, in Montréal, it was found that relative risk of injury was lower on cycle tracks (on-street bicycle paths with physical protection) than on comparable reference streets without cycling facility [34]. However, this protective effect may not be consistent across all bicycle facility types. Harris et al. [28] found that cycle tracks reduced the risk of injury; however, the same was not true for multiuse trails, bike lanes and shared lanes. In Vancouver, safety-relevant incidents were more common at intersections between a multiuse trail and roads than at reference intersections between two roads without bicycle-specific infrastructure [29]. Surprisingly, another study found a higher rate of safety-critical events when riding on a cycleway than when riding on a road without bicycle-specific treatment [35]. This apparent contradiction may be due to the relatively broad definition of bicycle infrastructure, which is not consistent from one study to another and from one jurisdiction to another.

\subsection{Research Objectives}

Although our understanding of contextual factors influencing cycling safety is improving, many variables remain underexplored. The effects of time and space on conflict occurrence have not yet been included as nonlinear effects in logit models. Many naturalistic cycling studies have been conducted in European settings [18,22,26,35]; however, to date, we have not found published results of such studies set in the Canadian context, where urban fabric and road geometries are very different. More importantly, cycling infrastructure's effect on safety has been evaluated in a variety of ways, but in many cases, category definitions were too broad, and the interaction between cycleway and road types is yet to be tested. Consequently, the aim of this paper is to evaluate cycleway and road types' combined effect on conflict occurrence with vehicles and with pedestrians, after controlling for individual and contextual factors. 


\section{Materials and Methods}

\subsection{Study Area: Montréal Agglomeration}

The Montréal agglomeration (2 million inhabitants in 2020) offers a unique case study, as it features both segregated and nonsegregated cycleways [36], which could be considered a hybrid between the American and European cycleway paradigms described by Furth [37]. Although the commuter cyclist mode share (2.5\% of all trips to work) [38] is humble in comparison to the European cycling capitals such as Amsterdam (21\% of all trips to work) [39], Montréal is among the most bike-friendly cities in North America, with a large and growing cycling network [40] and a longstanding bike-share service [41]. In this vein, Vancouver and Montréal are the only North American cities to belong to the Copenhagenize 2019 Index [42].

\subsection{Data}

\subsubsection{Primary Data: An Extensive Mobile Data Collection}

This paper relies on a quasinaturalistic study design to evaluate conflicts experienced by specially instructed cyclists. Four participants were involved in the mobile data collection: four graduate students in Urban Studies (three male and one female, respectively $25,28,29$ and 36 years old), selected by convenience, in good shape and with moderate urban cycling experience (more than two years of regular utilitarian cycling). All subjects gave their informed consent for inclusion before they participated in the study. The study was conducted in accordance with the Declaration of Helsinki, and the protocol was approved by the Ethics Committee of Institut national de la recherche scientifique (project No. CER 19-509).

All participants wore the same cycling jersey and rode similar bicycles (regular bikes similar to those used in other studies; Rocky Mountain RC 10 Performance, Vancouver, BC, Canada) provided by the research team. Bicycles were equipped with all the mandatory reflective pieces in the province of Québec (yellow reflectors facing forward and backward on both pedals, yellow reflectors facing sideways on both wheels, white reflector on handlebar facing forward and red reflector on the seatpost facing backward) and with a protective helmet (not required by law). Primary data were collected during daytime hours (8 a.m. to 6 p.m.), on six dry weather weekdays of June 2019, using an action camera mounted on the handlebar of the bicycle (Virb XE, Garmin International, Inc., Olathe, KS, USA) and a GPS watch on the cyclist's wrist (Forerunner 920 XT, Garmin International, Inc., Olathe, KS, USA).

The participants cycled alone on predefined routes for $87 \mathrm{~h}$ and for a total of $1199 \mathrm{~km}$. This extensive mobile data collection allows us to maximize spatial coverage of the study area and ensure a diversity of urban settings [43]. All data collection days started and ended at the university, thus allowing researchers to stay in touch with the participants, provide support when needed and supervise the data acquisition process closely. Cyclists were instructed to abide by the common traffic rules, ride at a safe speed for an urban context (between 15 and $20 \mathrm{~km} / \mathrm{h}$ ) and divide their routes into 40 min segments to simplify data processing.

\subsubsection{Secondary Data: Road and Cycleway Networks}

The cycleway and street networks used in this study are those publicly available through the open data platform of the City of Montréal [44,45]. For each network, types were grouped in order to have enough observations per category for bootstrapped statistical modeling (a minimum of 30 observations per category after undersampling, see Section 2.4.2). Grouped cycleway types correspond approximately to the four levels of cyclist separation presented by Furth [37]:

- Shared lane: regular street with no specific right-of-way for cyclists, designated by a "sharrow" (bicycle marking) on the tarmac to identify recommended bike routes.

- Bike lane: one-way dedicated lane for cyclists, separated by roadway stripping. 
- On-street bike path: two-way cyclist-only right-of-way located on the road. In Montréal, $73 \%$ of these paths are physically separated from vehicles by bollards, a jersey, a median or a fence [44].

- Off-street bike path: standalone path, in an independent right-of-way, dedicated to cyclists only (multiuse trails used by pedestrians and cyclists are excluded from the dataset).

Road types include:

- Local street: road with a volume of fewer than 3000 vehicles per day [46], whose main function is access to residences [47].

- Collector street: road with a volume of more than 1000 vehicles per day [46], which allows for transit on short distances, provides access to buildings of local importance and links between local and arterial roads [47].

- Arterial road: large road with a volume of between 5000 and 50,000 vehicles per day [46] that connects several neighborhoods together and allows for transit on relatively long distances [47].

Cycleway and road types are then coupled to create interaction variables (Figure 1).

\subsection{Data Reduction and Validation}

Each GPS point recorded by the watch was snapped to the nearest road link. The results were then validated by members of the research team using video clips to ensure the most accurate cycleway and road type classification. Two independent trained observers reviewed every video file recorded by the cameras through Vifeco, an open-source software developed in-house that allows observers to annotate several features directly on videos [48]. Conflict counts were performed using an iterative approach to ensure data quality and consistency. First, using 23 videos, the two observers were trained together to identify conflictual interactions with a pedestrian or a motorized vehicle (according to the traffic conflict definition mentioned in the introduction). Second, each observer individually annotated the rest of the videos.

Agreement between the annotations of the two independent observers reached 80\%. Two factors could explain this apparently low rate. First, many nonsevere conflicts may be arduous to distinguish from normal driving maneuvers or courteous behaviors. Second, all videos were reviewed blindly by two observers, meaning that each observer did not have access to the annotations of their colleague. In comparison, far from undermining their results, other studies relied on a data reduction process done by only one video observer $[15,16]$ or by two video observers without reporting agreement statistics $[22,35]$. Subsequently, the two observers watched the discordant events together to decide whether or not to include them in the final dataset, consulting a third expert (second author) when needed.

Conflicts with pedestrians that occurred on multiuse trails (that is, where pedestrians are allowed to walk), conflicts caused by our participant and conflicts that resulted from road users complying with traffic rules and signage (for example, legitimately parked cars) were excluded from the final dataset. 


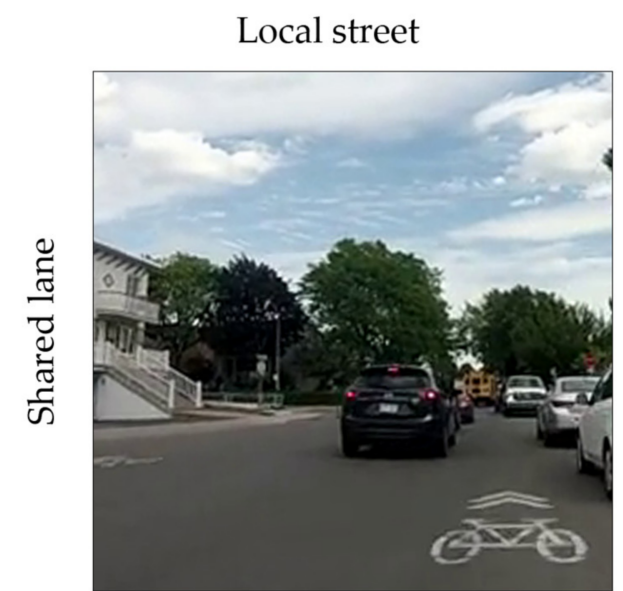

Collector street
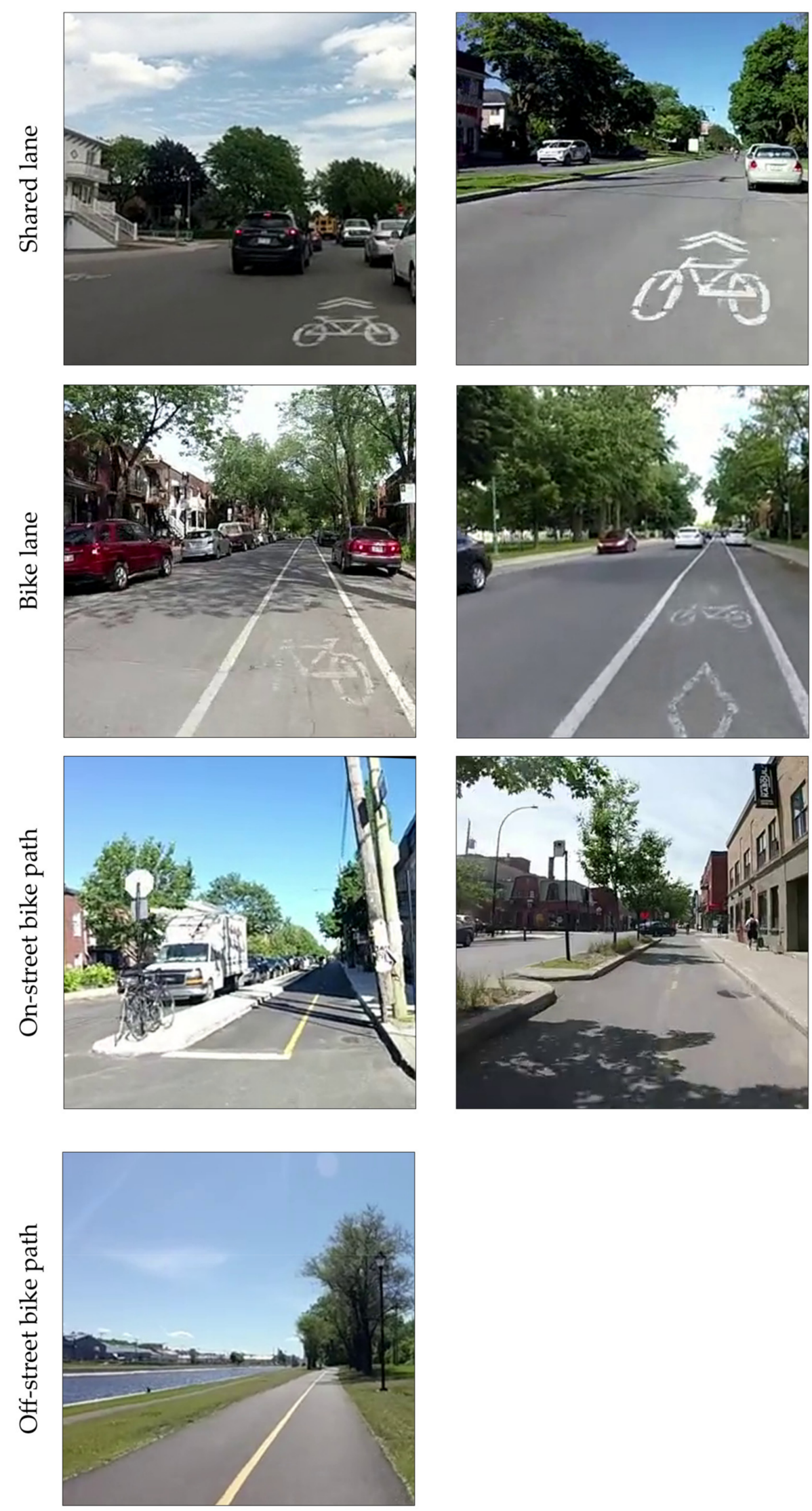
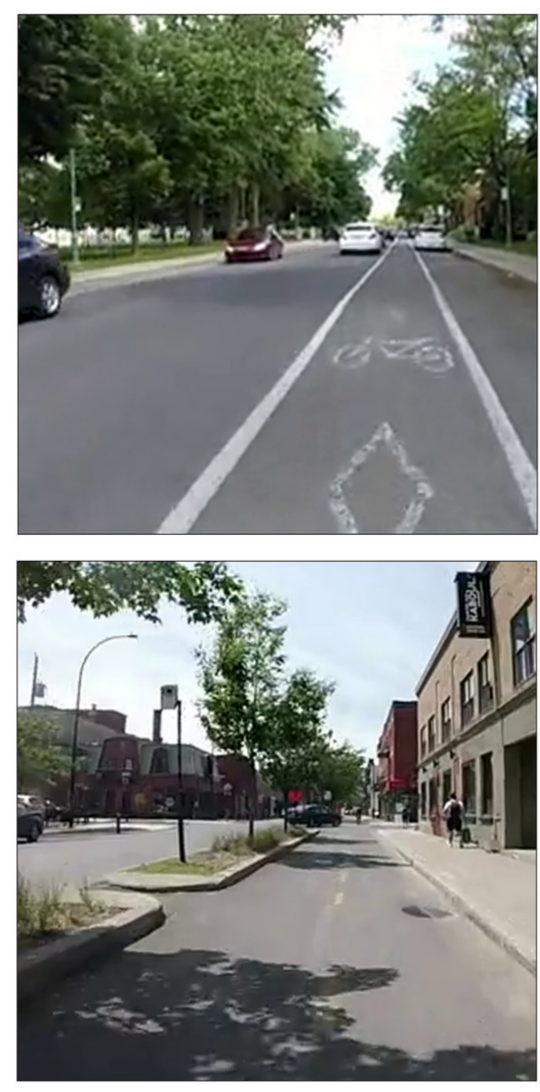

Arterial road
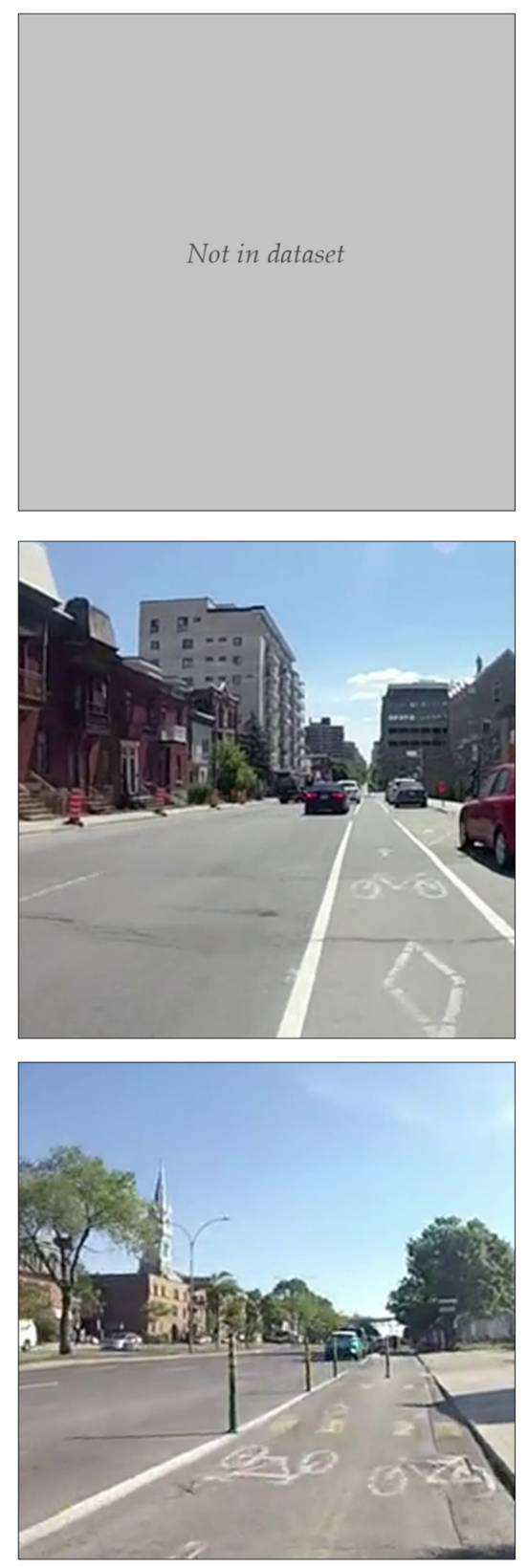

Figure 1. Cycleway and road types (interaction). Pictures taken from the video recordings of the handlebar camera. 


\subsection{Data Analysis}

\subsubsection{Variables and Hypotheses}

Data analysis was conducted in R version 4.0.3 [49]. First, conflict frequency (i.e., number of conflicts) and ratios per time and distance units were broken down by cycleway and road type. Second, using package "mgcv" [50], generalized additive models (GAMs) with logit distributions were fitted separately for vehicle and pedestrian conflict likelihood of occurrence as the outcome variable (i.e., likelihood of a conflict event to happen). Vehicle and pedestrian conflicts were separated for the analysis since they represent very different threats to cyclists and are not likely to follow the same patterns.

Several control variables were included in the models as a means to obtain unbiased coefficients (Table 1). First, traffic conflict likelihood is influenced by many individual factors, such as level of cycling experience, age, gender and riding habits [11,35], which could not all be included in our models for parsimony reasons and for lack of sufficient observations per category. Thus, participant ID was included as a way to account for individual variability among the four collectors. Second, the likelihood of conflict can differ from one day to another since traffic conditions are known to vary throughout the week [27]. The day of the week was thus introduced as a categorical linear effect. Third, we expected proximity to an intersection and to a bus stop to be positively associated with traffic conflict occurrence, as suggested by literature $[21,26]$. Fourth, likelihood of conflict could vary according to both time of day and space. We expected a greater number of traffic conflicts during peak traffic periods, namely the morning and afternoon rush hours $[16,35]$. Moreover, geographical position is likely to have a significant effect on the occurrence of traffic conflicts since many authors have shown that they are distributed in clusters rather than randomly [31]. Consequently, the time of day (number of min since 08:00) and geographical coordinates $(X, Y)$ were introduced as splines (nonlinear effects). Fifth, as the speed of the participant increases, traffic conflict occurrence is likely to increase as well [51]. Furthermore, including it as a spline allows testing if this effect is linear or not. Readers should note that slope was not controlled specifically, as was done in some collision [27] and conflict [19] studies. The terrain in Montréal is relatively flat, and geographical position is already included in the model, which should encompass some of the effect that slope could potentially have.

Table 1. Model specification.

\begin{tabular}{cccc}
\hline Type of Variable & Variable & Family & Effect \\
\hline \multirow{2}{*}{ Outcome } & Pedestrian conflict occurrence & Binomial & - \\
& Vehicle conflict occurrence & Binomial & - \\
\hline & Participant ID & Categorical & Linear \\
& Day of collection & Categorical & Linear \\
Control & Presence of an intersection within 15 m & Binomial & Linear \\
& Presence of a bus stop within 15 m & Binomial & Linear \\
& Time of day & Continuous & Smooth \\
& Geographical position & Continuous & Smooth \\
& Speed & Continuous & Smooth \\
\hline Predictor & Cycleway and road type (interaction) & Categorical & Linear \\
\hline
\end{tabular}

After controlling these factors, we expected cycleway and road type to significantly affect traffic conflict likelihood. For both vehicle and pedestrian conflicts, we did not expect shared lanes and bike lanes to reduce conflict likelihood [28]; in fact, bike lanes could even foster vehicle conflicts, as was noted by Beck et al. [52] in a motor vehicle passing distance study. For vehicle conflicts, we expected on-street and off-street bike paths to reduce vehicle conflict likelihood [34]. However, we expected conflict likelihood with a pedestrian to be higher on off-street bike paths [26,51]. Including road type as an interaction with cycleway type should reveal nuances in the associations between cycleway type and conflict likelihood. Indeed, one could reasonably expect a given cycling facility type to 
have a reduced protective effect when located on a street with more vehicular danger (i.e., an arterial road) than on a quieter street (i.e., a local street).

We did not include variables that directly evaluate vehicular traffic danger (such as traffic volumes and speeds and presence of heavy vehicles), even though they are known to increase conflict likelihood [16]. Real-time traffic indicators could be calculated using dynamic traffic counts on the videos captured by the handlebar camera; however, this process would add to the already labor-intensive video reviewing process. Nevertheless, as far as the models in this study are concerned, the temporal and spatial control variables and the road type interaction variable are likely to serve as proxies for vehicular traffic danger indicators.

\subsubsection{Dataset Composition for Logit Modeling}

Our dataset was composed of conflict events and baseline events, i.e., random points in the dataset where no conflict occurred [18]. In order to avoid the class imbalance problem in our dataset (very large number of baseline events in comparison to conflict events), we used a resampling technique of undersampling (reducing the number of baseline events for it to correspond to approximately 2 times the number of conflict events) $[18,24]$. In other words, first, two datasets were produced: one with vehicle conflicts and one with pedestrian conflicts. Then, to these two separate datasets, we appended a certain number of baseline events, corresponding to twice the number of conflicts, randomly drawn from the rest of the dataset. One problem with this sampling method is the risk of randomly selecting a nonrepresentative sample of baseline events, hence introducing bias in the estimation of the model parameters. To overcome this problem, we bootstrapped the sampling and model fitting process (1000 iterations) and then extracted mean and percentiles ( $2.5 \%$ and $97.5 \%$ to form a $95 \%$ confidence interval) from the parameters (i.e., coefficients, fit statistics, etc.). Reported model results are, thus, distributions of parameters, rather than a single estimate for each predictor. Interpretation is, however, similar to that of a regular logit model, in the sense that predictors are considered significant when their odds-ratio upper and lower confidence interval limits are both greater or less than 1.

\section{Results}

\subsection{Exploratory Data Analysis}

This study relies on $5208 \mathrm{~min}$ of on-street and off-street cycling, for a total of $1199 \mathrm{~km}$ (Table 2). Most of the riding took place in the central districts; nevertheless, the data collection covers the whole island of Montréal (Figure 2). Video reviewers identified 465 conflicts with vehicles and 209 conflicts with pedestrians. For the major part, cyclists rode on regular streets without cycling facility (3213 $\mathrm{min}, 61.7 \%$ ). The most frequent cycling facility type taken by the participants is the off-street bike path (541 $\mathrm{min}, 10.4 \%$ ).

For vehicle conflicts, on nonprotected cycling facilities (shared lane and bike lane), we measured rates ranging from 4.0 conflicts per $60 \mathrm{~min}$ for a shared lane on a local street to 13.0 conflicts per $60 \mathrm{~min}$ for a bike lane on a collector street. These high rates contrast with those of on-street bike paths located on local streets ( 2.9 conflicts per $60 \mathrm{~min}$ ), collector streets ( 3.0 conflicts per $60 \mathrm{~min}$ ) and arterial roads ( 1.3 conflicts per $60 \mathrm{~min}$ ). The picture is just as compelling for off-street bike paths: notwithstanding the participants' high exposure to this facility type (541 min, 10.4\%), they experienced very few conflicts (13 conflicts, $2.8 \%$ ), leading to the second lowest rate of conflicts ( 1.4 conflicts per $60 \mathrm{~min}$ ). Readers should note that although it may seem surprising to experience a conflict with a vehicle on an off-street facility, the situation may arise when cyclists are approaching a road intersection or a driveway entrance, for example. 
Table 2. Dataset description.

\begin{tabular}{|c|c|c|c|c|c|c|c|c|c|c|c|c|}
\hline \multirow{4}{*}{ Cycleway and Road Type ${ }^{1}$} & \multicolumn{4}{|c|}{ Cyclists' Exposure } & \multicolumn{8}{|c|}{ Conflict Frequency } \\
\hline & \multicolumn{2}{|c|}{ Minutes } & \multicolumn{2}{|c|}{ Kilometers } & \multicolumn{4}{|c|}{ Vehicle } & \multicolumn{4}{|c|}{ Pedestrian } \\
\hline & & & & & & & per & per & & & per & per \\
\hline & $\mathbf{n}$ & $\%$ & $\mathbf{n}$ & $\%$ & $\mathbf{n}$ & $\%$ & $\begin{array}{c}60 \\
\min \end{array}$ & $\begin{array}{l}100 \\
\mathbf{k m}\end{array}$ & $\mathbf{n}$ & $\%$ & $\begin{array}{l}60 \\
\min \end{array}$ & $\begin{array}{l}100 \\
\text { km }\end{array}$ \\
\hline 01 Street without cycling facility (ref.) & 3213 & 61.7 & 791 & 66.0 & 290 & 62.4 & 5.4 & 36.7 & 82 & 39.2 & 1.5 & 10.4 \\
\hline 02 Shared lane-local street & 286 & 5.5 & 70 & 5.8 & 19 & 4.1 & 4.0 & 27.1 & 11 & 5.3 & 2.3 & 15.7 \\
\hline 03 Shared lane-collector street & 110 & 2.1 & 32 & 2.7 & 9 & 1.9 & 4.9 & 28.1 & 2 & 1.0 & 1.1 & 6.2 \\
\hline 04 Bike lane-local street & 203 & 3.9 & 48 & 4.0 & 35 & 7.5 & 10.3 & 72.9 & 5 & 2.4 & 1.5 & 10.4 \\
\hline 05 Bike lane-collector street & 254 & 4.9 & 57 & 4.8 & 55 & 11.8 & 13.0 & 96.5 & 10 & 4.8 & 2.4 & 17.5 \\
\hline 06 Bike lane-arterial road & 174 & 3.3 & 29 & 2.4 & 28 & 6.0 & 9.7 & 96.6 & 4 & 1.9 & 1.4 & 13.8 \\
\hline 07 On-street bike path-local street & 103 & 2.0 & 18 & 1.5 & 5 & 1.1 & 2.9 & 27.8 & 6 & 2.9 & 3.5 & 33.3 \\
\hline 08 On-street bike path-collector street & 138 & 2.6 & 25 & 2.1 & 7 & 1.5 & 3.0 & 28.0 & 14 & 6.7 & 6.1 & 56.0 \\
\hline 09 On-street bike path-arterial road & 186 & 3.6 & 20 & 1.7 & 4 & 0.9 & 1.3 & 20.0 & 14 & 6.7 & 4.5 & 70.0 \\
\hline 10 Off-street bike path & 541 & 10.4 & 109 & 9.1 & 13 & 2.8 & 1.4 & 11.9 & 61 & 29.2 & 6.8 & 56.0 \\
\hline Total & 5208 & 100.0 & 1199 & 100.0 & 465 & 100.0 & 5.4 & 38.8 & 209 & 100.0 & 2.4 & 17.4 \\
\hline
\end{tabular}

${ }^{1}$ Shared lane on arterial road, a very rare type, is absent from our dataset.

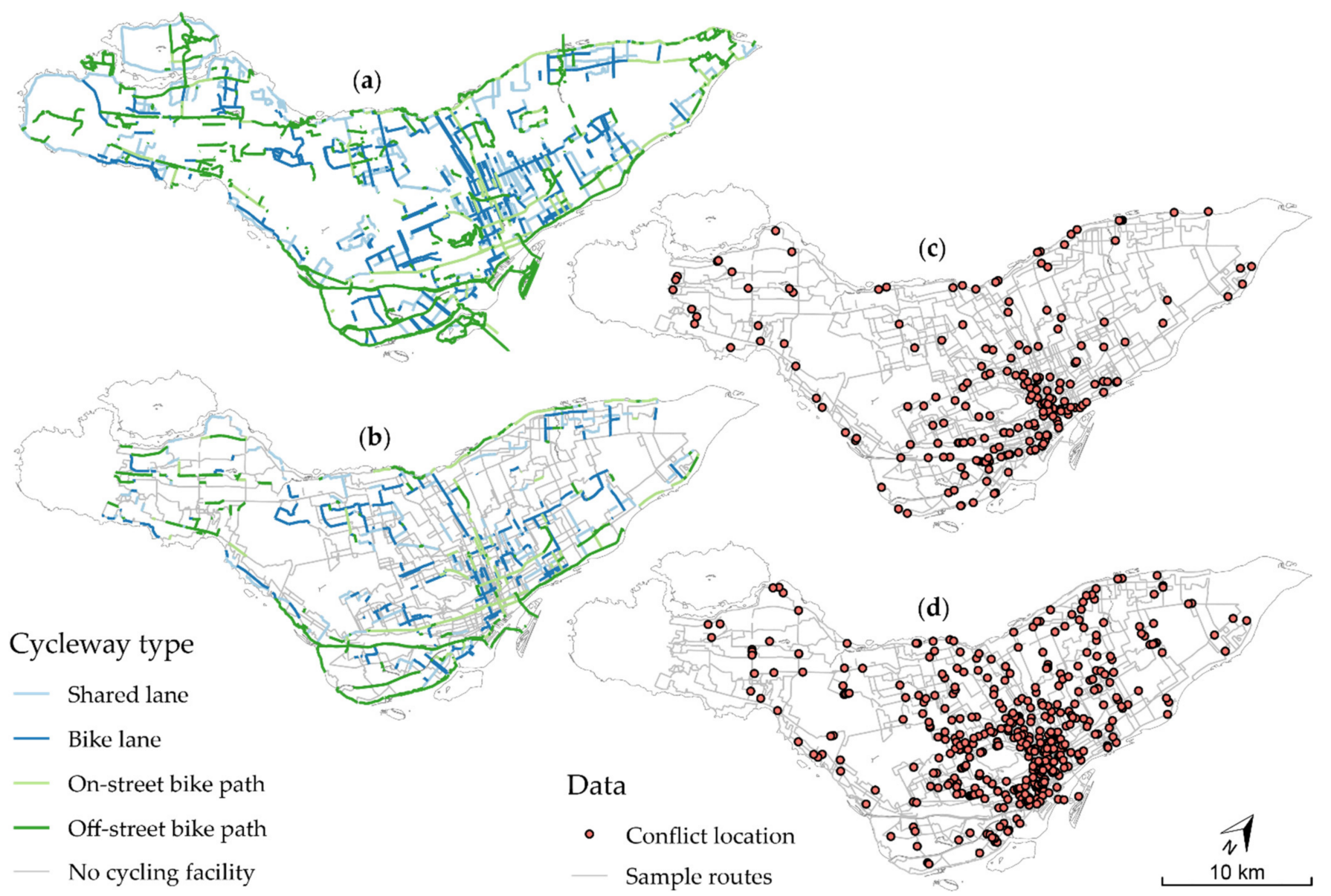

Figure 2. Secondary, primary and processed data. (a) Montréal's cycling network; (b) mobile data collection (sample routes); (c) pedestrian conflict locations; (d) vehicle conflict locations.

Pedestrian conflict rates follow an opposite trend. Although most conflicts occurred on streets without cycling facility ( 82 conflicts; $39.2 \%$ ), it is much less than one could have expected if conflict occurrence corresponded with exposure (3213 $\mathrm{min}, 61.7 \%$ ). Nonprotected facilities (shared lanes and bike lanes) display low rates of pedestrian conflicts. 
The most eloquent example is the shared lane on a collector street: cyclists from our data collection only experienced 1.1 conflicts per $60 \mathrm{~min}$. On-street bike paths have much higher rates of conflicts with pedestrians: on collector streets, cyclists from the data collection were subject to 6.1 conflicts per $60 \mathrm{~min}$. While accounting for $10.4 \%$ of cyclists' total exposure in minutes, $29.2 \%$ of the conflicts with pedestrians took place on off-street bike paths, making it the infrastructure with the highest number of conflicts per $60 \mathrm{~min}$ (6.8 conflicts).

\subsection{Model Results}

Model results are reported in Table 3. Fit statistics show that the models explain only a small proportion of the total variance (Vehicle: $R^{2}=0.16$, CI $(95 \%)=0.14-0.19$; deviance explained $=0.16$, CI $(95 \%)=0.14-0.18$. Pedestrian: $\mathrm{R}^{2}=0.16$, CI $(95 \%)=0.12$ 0.20 ; deviance explained $=0.16, \mathrm{CI}(95 \%)=0.13-0.20$.). This reflects the fact that conflict likelihood depends upon a broad spectrum of factors that are not modeled here. However, these statistics do not undermine the ability of the models to reveal significant associations between cycleway type (predictor variable) and conflict likelihood (outcome variable), which is the main objective of this paper.

Table 3. Model results.

\begin{tabular}{|c|c|c|c|c|}
\hline \multirow{3}{*}{ Parameter } & \multirow{2}{*}{\multicolumn{2}{|c|}{$\begin{array}{c}\text { Vehicle } \\
\text { Odds Ratio (OR) }\end{array}$}} & \multirow{2}{*}{\multicolumn{2}{|c|}{$\begin{array}{c}\text { Pedestrian } \\
\text { Odds Ratio (OR) }\end{array}$}} \\
\hline & & & & \\
\hline & Mean & $C I(95 \%)^{a}$ & Mean & CI $(95 \%)^{a}$ \\
\hline (Intercept) & 0.58 & 0.470 .71 & 0.42 & 0.310 .60 \\
\hline \multicolumn{5}{|l|}{ Control variables } \\
\hline \multicolumn{5}{|l|}{ Linear terms } \\
\hline Participant 1 & Ref. & & Ref. & \\
\hline Participant 2 & 0.70 & 0.560 .90 & 0.75 & 0.541 .04 \\
\hline Participant 3 & 0.90 & 0.721 .16 & 0.55 & 0.390 .79 \\
\hline Participant 4 & 0.91 & 0.731 .13 & 0.70 & 0.491 .01 \\
\hline Wednesday, June 12 & Ref. & & Ref. & \\
\hline Monday, June 17 & 0.99 & 0.781 .29 & 0.97 & 0.671 .37 \\
\hline Tuesday, June 18 & 0.90 & 0.711 .15 & 1.45 & 1.022 .06 \\
\hline Wednesday, June 19 & 1.19 & 0.891 .54 & 0.90 & 0.601 .33 \\
\hline Friday, June 21 & 1.37 & 1.011 .86 & 0.72 & 0.441 .15 \\
\hline Intersection within $15 \mathrm{~m}$ & 1.12 & 0.931 .33 & 1.28 & 0.971 .67 \\
\hline Bus stop within $15 \mathrm{~m}$ & 1.04 & 0.821 .36 & 0.68 & 0.471 .01 \\
\hline \multicolumn{5}{|l|}{ Smooth terms (splines) } \\
\hline Time of the day $\left(\mathrm{edf}^{\mathrm{b}}\right)$ & 5.11 & 2.216 .65 & 1.31 & 1.003 .04 \\
\hline Time of the day ( $p$-value) & 0.04 & 0.000 .41 & 0.58 & 0.120 .98 \\
\hline Geographical position (edf ${ }^{b}$ ) & 10.98 & 8.6813 .56 & 7.79 & 5.1110 .37 \\
\hline Geographical position ( $p$-value) & 0.00 & 0.000 .00 & 0.05 & 0.000 .25 \\
\hline Speed $\left(\right.$ edf $\left.^{b}\right)$ & 4.85 & 4.155 .84 & 2.33 & 1.343 .03 \\
\hline Speed ( $p$-value) & 0.00 & 0.000 .00 & 0.00 & 0.000 .01 \\
\hline \multicolumn{5}{|l|}{ Predictor variables } \\
\hline 01 Street without cycling facility & Ref. & & Ref. & \\
\hline 02 Shared lane-local street & 0.76 & 0.561 .06 & 1.64 & 1.072 .70 \\
\hline 03 Shared lane-collector street & 1.28 & 0.812 .24 & 1.15 & 0.523 .80 \\
\hline 04 Bike lane-local street & 2.10 & 1.443 .20 & 1.07 & 0.611 .98 \\
\hline 05 Bike lane-collector street & 2.66 & 1.933 .80 & 1.64 & 1.042 .94 \\
\hline 06 Bike lane-arterial road & 1.21 & 0.821 .92 & 0.78 & 0.421 .62 \\
\hline 07 On-street bike path-local street & 0.50 & 0.300 .99 & 1.68 & 0.834 .85 \\
\hline 08 On-street bike path-collector street & 0.44 & 0.280 .70 & 3.43 & 1.817 .75 \\
\hline 09 On-street bike path-arterial road & 0.19 & 0.120 .33 & 2.63 & 1.435 .58 \\
\hline 10 Off-street bike path & 0.30 & 0.230 .39 & 3.95 & 2.756 .12 \\
\hline
\end{tabular}


Table 3. Cont.

\begin{tabular}{|c|c|c|c|c|}
\hline \multirow{3}{*}{ Parameter } & \multirow{2}{*}{\multicolumn{2}{|c|}{$\begin{array}{c}\text { Vehicle } \\
\text { Odds Ratio (OR) }\end{array}$}} & \multirow{2}{*}{\multicolumn{2}{|c|}{$\begin{array}{c}\text { Pedestrian } \\
\text { Odds Ratio (OR) }\end{array}$}} \\
\hline & & & & \\
\hline & Mean & CI $(95 \%)^{a}$ & Mean & CI $(95 \%)^{a}$ \\
\hline \multicolumn{5}{|l|}{ Fit statistics } \\
\hline R squared (adjusted) & 0.16 & 0.140 .19 & 0.16 & 0.120 .20 \\
\hline Deviance explained & 0.16 & 0.140 .18 & 0.16 & 0.130 .20 \\
\hline
\end{tabular}

${ }^{\mathbf{a}} \mathrm{CI}$ : confidence interval. Statistically significant values are shown in bold. ${ }^{\mathbf{b}}$ edf: estimated degrees of freedom, i.e., number of knots (inflection points) in the spline. Consequently, a higher edf value means a greater spline variability and a greater influence on the response variable. Regarding the smooth terms, confidence intervals represent edf and $p$-value variations among the 1000 models. Thus, a spline is deemed significant when its $p$-value is below or equal to $0.05,95 \%$ of the time.

\subsubsection{Control Variables}

Participant and day of collection are significant for the vehicle and the pedestrian models. Proximity to an intersection and to a bus stop did not significantly influence likelihood of conflict during our collection, although one can notice that the odds ratio of the intersection variable is almost significant for both models. Time of day is almost significant for the vehicle model, and geographical position is significant for both models, which means that conflict likelihood did follow nonlinear temporal and spatial trends during our data collection. Such results stress the importance of including these control variables when modeling traffic conflict likelihood; nevertheless, one must be careful with their interpretation. While having the potential to significantly influence traffic conflict likelihood, their results cannot be generalized beyond the scope of this data collection.

Although speed was initially included as a control variable in the model, it yields results worth analyzing by themselves (Figure 3). Below $10 \mathrm{~km} / \mathrm{h}$, speed is associated with a lower conflict likelihood. As speed increases, its risk-reducing effect evaporates, until conflict likelihood reaches a stability point, approximately at $15 \mathrm{~km} / \mathrm{h}$ for the vehicle model and $20 \mathrm{~km} / \mathrm{h}$ for the pedestrian model. Beyond these thresholds, conflict likelihood is constant and hovers around zero, which means that speed no longer has a significant effect. However, our results do not show the severity of the conflict, which is known to be associated with cyclist speed [11].

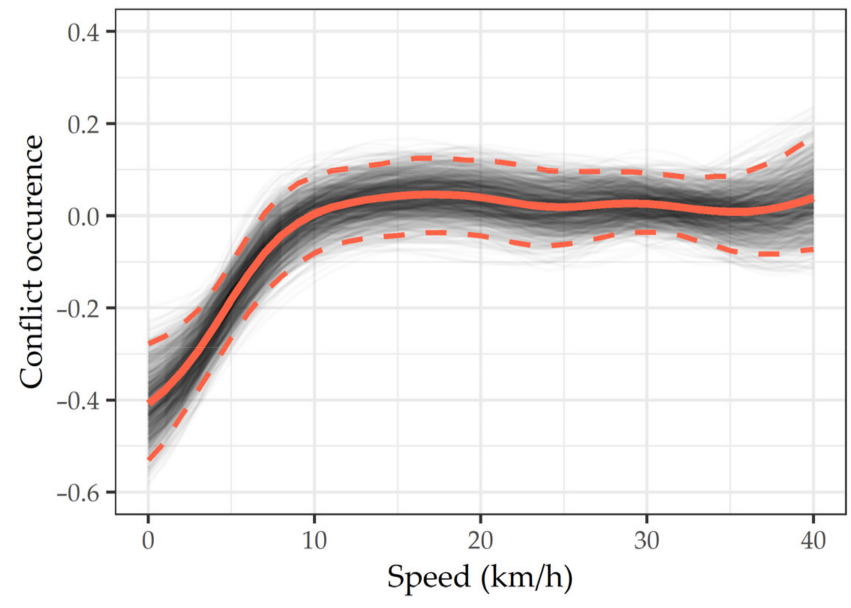

(a)

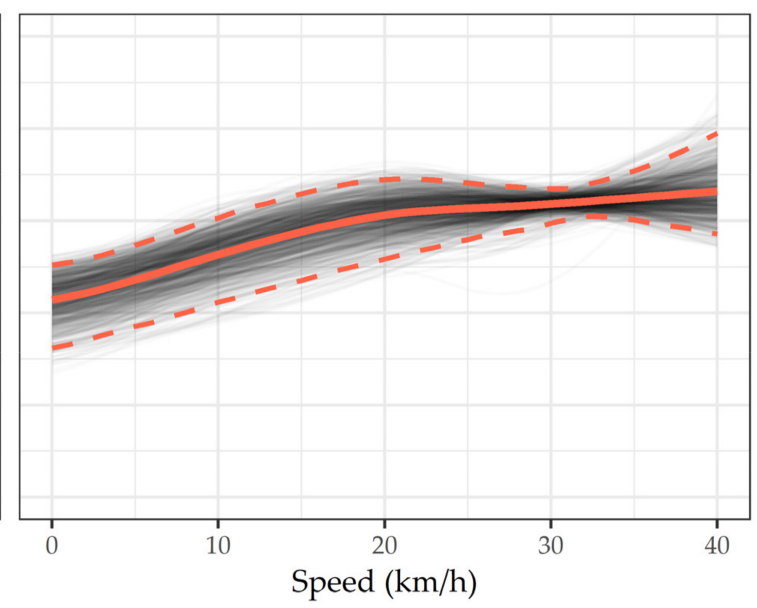

(b)

Figure 3. Cyclist speed's marginal effect on conflict occurrence with (a) a vehicle and (b) a pedestrian. In other words, this graph depicts the independent contribution of cyclist's speed on the response variable (conflict occurrence, $0-1$ ) centered on zero, once controlled for all the other independent variables. A negative conflict occurrence can thus be interpreted as a negative effect on the likelihood of conflict. The solid red line represents the mean of all model splines, the dashed red lines represent the confidence interval (95\%) and the translucent black lines in the background represent each individual spline $(n=1000)$. 


\subsubsection{Vehicle Conflict Likelihood Predictors}

Model results show that some, but not all, cycleway types significantly influence vehicle conflict likelihood (Table 3). Cycling on a shared lane had no significant effect on conflict likelihood. When located on a local $(\mathrm{OR}=2.10 ; \mathrm{CI}(95 \%)=1.44-3.20)$ or a collector street $(\mathrm{OR}=2.66$; $\mathrm{CI}(95 \%)=1.93-3.80)$, cyclists on a bike lane were more than twice as likely to experience a conflict with a vehicle than when cycling on a reference street without cycling facility. However, when the bike lane was located on an arterial road, that effect was not significant. On the other hand, cycling on an on-street bike path is associated with a significantly lower probability of conflict with a vehicle, no matter the type of street on which they are located: local street $(\mathrm{OR}=0.50 ; \mathrm{CI}(95 \%)=0.30-0.99)$, collector street $(\mathrm{OR}=0.44 ; \mathrm{CI}(95 \%)=0.28-0.70)$ and arterial road $(\mathrm{OR}=0.19 ; \mathrm{CI}(95 \%)=0.12-0.33)$. Not surprisingly, the same is true for off-street bike paths $(\mathrm{OR}=0.30$; $\mathrm{CI}(95 \%)=0.23-0.39)$.

\subsubsection{Pedestrian Conflict Likelihood Predictors}

Conflict likelihood with a pedestrian also varies according to infrastructure type (Table 3). Cycling on a shared lane on a local street $(\mathrm{OR}=1.64$; CI $(95 \%)=1.07-2.70)$ or on a bike lane on a collector street $(\mathrm{OR}=1.64$; $\mathrm{CI}(95 \%)=1.04-2.94)$ has a slightly significant increasing effect on conflict likelihood. When located on other types of roads, this effect is not significant, meaning that the probability of experiencing a conflict with a pedestrian is no different on those facilities than on a reference street without cycling facility. On-street bike paths are associated with higher likelihoods of conflict: when located on a collector street $(\mathrm{OR}=3.43 ; \mathrm{CI}(95 \%)=1.81-7.75)$ or on an arterial road $(\mathrm{OR}=2.63$; $\mathrm{CI}(95 \%)=1.43-5.58)$, they expose cyclists to a probability of traffic conflict higher than the reference level. However, that effect is not significant when the on-street bike path is located on a local street. Off-street bike paths show an even greater association: when cycling on such facilities, cyclists from our data collection were $3.95(\mathrm{CI}(95 \%)=2.75-6.12)$ times more likely to experience a conflict with a pedestrian than when cycling on a street without cycling facility (reference).

\section{Discussion}

\subsection{Limitations}

Conflict severity has not been evaluated in this study; however, it could bring relevant nuances to our conclusions in future research. Participants involved in this study are all graduate students in Urban Studies, which is not a representative sample of the cyclist population. Nonetheless, using a small and rather homogeneous sample of cyclists on schematically allocated routes has the advantage of reducing variance attributable to riding styles and route sampling frequency [22]. Other studies asked their participants to identify traffic conflicts themselves, eliminating researcher bias in the identification of the conflicts [18]. However, our approach has the advantage of standardizing conflict identification among all participants.

\subsection{Contribution to Scholarly Knowledge}

This paper is a novel attempt at modeling cyclists' exposure to traffic conflict risk using an extensive mobile data collection. The dataset used in this study includes many nonsevere events, which are often disregarded in other studies that focus on critical events $[18,35]$. Moreover, it brings nuances to the generally accepted statement that cycling infrastructure is safer for cyclists [9]. Indeed, its protective effect depends upon cycleway type (in interaction with road type) and conflict partner (vehicle and pedestrian).

\subsubsection{Safety Incidence Rates (SIRs) among Other Conflict Studies}

Table 4 shows an overview of the incidence rates presented by other studies. While most studies measured rates below 1 event per 60 min and 5 events per $100 \mathrm{~km}$, one paper used a broader definition of conflict (encompassing all traffic violations) and measured 3 and 17 events per $60 \mathrm{~min}$ and $100 \mathrm{~km}$ [21]. The present study measured high incidence 
rates ( 5 and 2 conflicts with vehicles and pedestrians per $60 \mathrm{~min}$, see Table 2 for further details). Directly comparing incidence rates from one paper to another is challenging due to the variety of geographical contexts (e.g., country and city size) and of conflict definitions used by the authors. Among other factors, higher rates in our study may reflect that notwithstanding its strong cycling community and rapidly evolving cycling infrastructure, Montréal is still a North American metropolis with large vehicle and pedestrian flows, as well as many car-oriented street designs [7].

Table 4. Safety incidence rates of some cycling safety studies.

\begin{tabular}{llrrrrr}
\hline \multirow{2}{*}{ Select Cycling Safety Studies } & \multicolumn{1}{c}{ Area } & \multicolumn{2}{c}{ Dataset Size } & \multicolumn{3}{c}{ Safety Incidence Rates } \\
\cline { 3 - 7 } & & Events (n) & min & km & Per 60 min & Per 100 km \\
\hline Johnson et al. [20] & Melbourne, Australia & 54 & 7658 & - & $0.42^{*}$ & - \\
Gustafsson and Archer [22] & Stockholm, Sweden & 220 & 14,400 & $4910^{*}$ & $0.92^{*}$ & $4.48^{*}$ \\
Dozza and Werneke [18] & Gothenburg, Sweden & 63 & 6840 & $1549^{*}$ & $0.55^{*}$ & $4.07^{*}$ \\
Schleinitz et al. [35] & Chemnitz, Germany & 77 & 22,320 & $5280^{*}$ & $0.21^{*}$ & 1.44 \\
Hamann and Peek-Asa [21] & Iowa City, USA & 180 & $3436^{*}$ & $1078^{*}$ & 3.14 & 16.70 \\
\hline
\end{tabular}

* Rates derived from other data presented in the paper.

\subsubsection{Nonprotected Bike Lanes: Not the Thought That Counts}

Bike lanes not only fail to prevent conflicts with vehicles, but also seem to foster them. In this study, bike lanes were often illegally occupied by motorists as if it were a residual space to perform numerous tasks that cannot be done in the moving vehicle lane. The most frequent example is the vehicle parked in the bike lane (Figure 4a). Lack of physical separation also makes it easy for car drivers to partially encroach on the bike lane when engaging in some maneuvers, such as turning right at an intersection (Figure $4 \mathrm{~b}$ ). In line with the residual space-use of the bike lane, motorists often take advantage of it to enter and exit their vehicle away from moving motorized traffic (Figure 4c). All these situations force cyclists to swerve away from the encroachment point towards the center of the street (when the conflict stems from a parked vehicle) or towards the curb or the parking lane (when the conflict is caused by a vehicle in the moving lane). This is particularly worrisome when analyzed in conjunction with the findings from Beck et al. [52]: in their study analyzing motor vehicle passing distance with cyclists, they found that bike lanes were associated with significantly shorter passing distances than regular streets without cycling facility. This association between safety events and bike lanes (more conflicts and shorter passing distance) may seem harmless in itself since most collision and injury studies do not report similar significant associations [28,33]. However, when experienced repeatedly, these events may have an effect on cycling motivation, especially for safetyconscious individuals [53], and may lead in some cases to minor crashes, which are often absent from collision and injury databases due to underreporting bias [10].

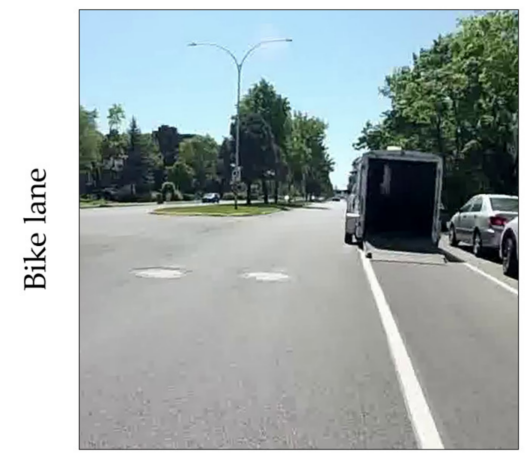

(a)

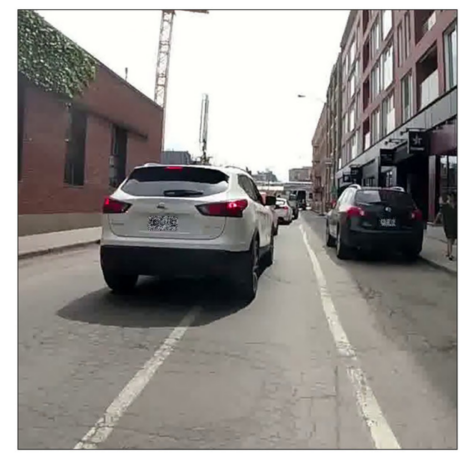

(b)

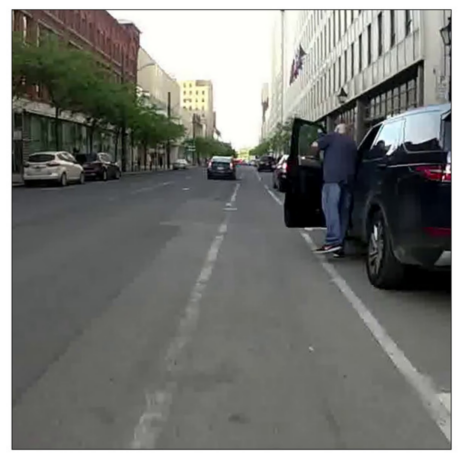

(c)

Figure 4. Vehicle conflicts on bike lanes located on collector streets: (a) parked car, (b) lane encroachment and (c) access to vehicle. 


\subsubsection{The Backfiring Effect of Physically Separated Cycling Facilities}

On-street and off-street bike paths strongly decrease vehicle conflict likelihood. This supports previous Canadian studies that found lower relative risks of injury on protected cycle tracks than on reference streets without cycling facility [33,34]. However, this protective effect seems to attract more than just cyclists.

Other vulnerable road users (mostly pedestrians) often seek refuge in the bike path, even if a dedicated sidewalk is available nearby. In the example shown in Figure 5a, the pedestrians choose to walk on the bike path probably because the sidewalk is much closer to the road, i.e., to vehicular danger and its associated noise and air pollution. Among pedestrians, many conflict partners were joggers (Figure $5 b$ ), for whom the bike path is a much more comfortable infrastructure than the sidewalk's uneven surface. Bike paths are also used as a residual space by neighbors for their garbage collection bins (Figure 5c). Note that although bins in themselves were not counted as conflicts, pedestrians manipulating them were. Such findings seem congruent with those of Schleinitz et al. [35] who measured higher safety incidence rates (SIRs) of conflicts with other cyclists and pedestrians on cycling infrastructure than on regular roads.

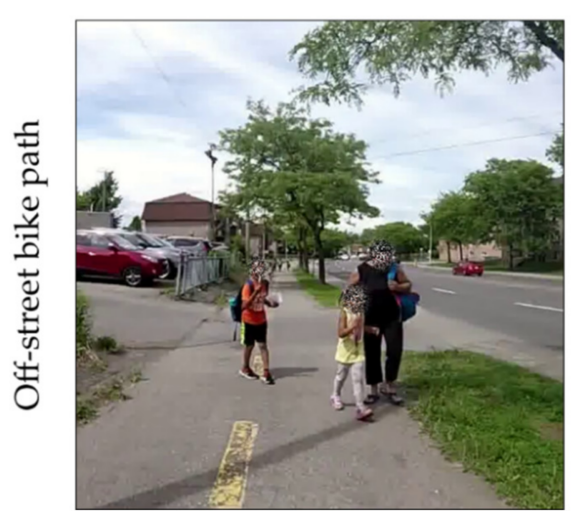

(a)

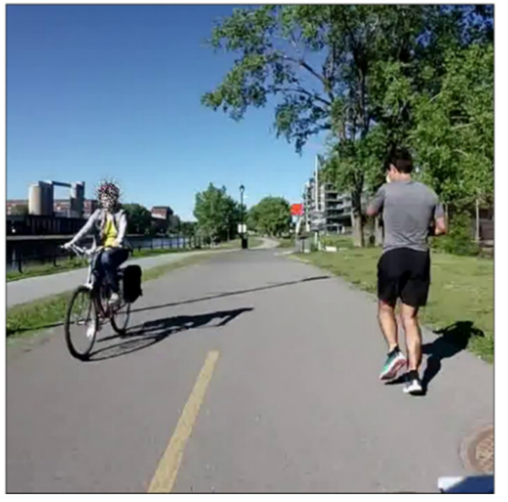

(b)

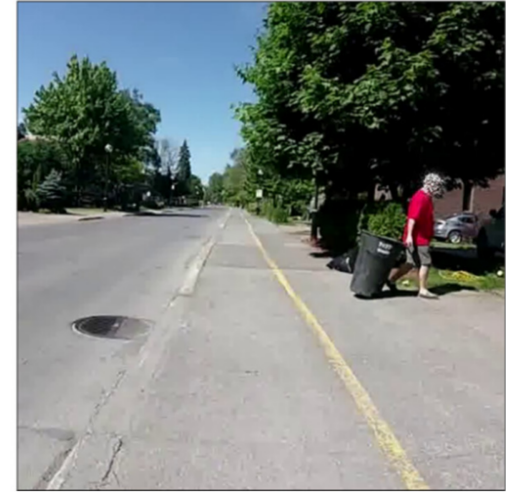

(c)

Figure 5. Pedestrian conflicts on off-street bike paths with (a) a walker, (b) a jogger and (c) other.

One result that may seem surprising at first glance is the slightly higher likelihood of conflict with a pedestrian on shared lanes that are located on a local street and on bike lanes that are located on a collector street. First, for both predictors, this effect is much smaller than it is for on-street and off-street bike paths. Second, as for shared lanes, it may reflect that the lower traffic volumes increase pedestrians' confidence to walk in the street rather than on the sidewalk. Third, as for bike lanes, this effect is likely related to the presence or absence of physical separation features. Indeed, while bollards were present in only $3 \%$ of the baseline events located on collector street bike lanes, they were present in $20 \%$ of the conflicts with pedestrians that occurred on collector street bike lanes.

\subsubsection{The Relevance of Cycleway and Road Type Interaction Variables}

Cycling facilities do not have the same effect on conflict likelihood depending on the type of road on which they are located. Such interaction variables are seldom found in the literature. In the vehicle model, bike lanes increase conflict likelihood when located on local and collector streets; however, this effect is not significant for bike lanes located on arterial roads. Higher traffic flows and the more transit-focused nature of these roads may explain why fewer vehicles park in the bike lane for a quick stop. As for pedestrians, conflict likelihood is higher on on-street bike paths that are located on arterial and collector roads; however, this effect is not significant when the bike path is located on a local street. This may be linked to the lower pedestrian volumes typically measured on local streets.

Note that one must be cautious with the interpretation of the interaction variable coefficients: we do not recommend installing bike lanes on arterial roads. Even if our 
results show that vehicle conflict likelihood is lower when the bike lane is located on an arterial road than on a collector or local street, conflict and collision severity may be higher on arterial roads due to the higher traffic volumes and speeds, as well as the presence of heavy vehicles. In this vein, bike lanes on arterial roads could prove to be more dangerous overall than bike lanes on collector streets.

\subsection{Implications for Decision Makers}

\subsubsection{Cycleway Design Considerations}

Understanding the combined effect of cycleway and road type on conflict likelihood could be relevant to urban planners when (1) identifying which cycling facility type to build along a given corridor and (2) anticipating potential conflicts and installing protection features.

Public guidelines in Québec recommend allocating shared lanes only on streets with low vehicle flows [54]. Although not contradicting this recommendation, our results prove that likelihood of conflict with a vehicle is no different on streets with or without a "sharrow", which may raise questions on the merits of such a facility type.

Bike lanes that are not physically segregated from traffic should be avoided, especially on streets where parking demand is high in comparison to the available spots and where car drivers may be tempted to temporarily park the vehicle in the bike lane to run an errand. This implies the use of physical separation features, be they simple solutions such as bollards, larger investments such as medians, or any element more substantial than paint.

On on-street and off-street bike paths, the few vehicle conflicts experienced by the cyclists from this data collection were intersection- or driveway-related, which are locations where the physical separation is breached. This stresses the need for better integration of cycling facilities at intersections to ensure that the safe cycling conditions are continuous throughout cycling routes [12]. It also supports current provincial guidelines, which discourage planners from designing on-street two-way bike paths specifically because of the potential conflicts at driveways and intersections [54]. Urban planners could, for instance, extend the cycleway protection into the intersection by building a corner island that gives turning vehicles a better sight of crossing cyclists [55].

Planners must nevertheless be sensitive to the backfiring effect that physically protected designs may have, i.e., pedestrians using them. This effect is only briefly addressed in current public guidelines [54]. First, planners could accommodate pedestrians by providing them with comfortable infrastructure further away from traffic than the bike path, eliminating in the first place the comparable advantage of walking on the bike path rather than the footpath. Second, clear, frequent and highly visible road marking and signage must be placed to designate cyclist-only rights-of-way. Signage is especially important in northern cities like Montréal, where snowplowing and application of strong abrasives, which are necessary to maintain the roads during the harsh winter months, can rapidly fade away the road markings.

\subsubsection{Education}

Pedestrians (especially those wearing headphones) could use bike paths in a safer manner by walking or running in the opposite direction of cyclist traffic, making it easier to yield the way to oncoming cyclists. Education programs and awareness-raising patrols could help pedestrians and cyclists to better share the paths. However, such programs must not replace the provision of decent infrastructure for both pedestrians and cyclists.

\section{Conclusions}

The aim of this study was to evaluate cycleway and road types' combined effect on cycling conflict occurrence with vehicles and with pedestrians. Bootstrapped generalized additive model (GAM) results show that not all cycleway types are created equal when it comes to protecting their users from conflicts. Bike lanes are more vehicle-conflict prone 
than regular streets, which is counterproductive. Securing them with simple physical features, such as bollards, could discourage their use as a residual space for vehicles. On-street and off-street bike paths offer protection from conflicts with vehicles (except at driveways or at intersections), which is consistent with the literature about cycling safety. However, they fail to protect cyclists from conflicts with pedestrians. While the former may have more severe outcomes than the latter, urban planners must not neglect the dissuasive effect that experiencing frequent nonsevere conflicts can have on cycling motivation. Indeed, having to avoid many pedestrians while cycling may translate into a higher level of stress and a less efficient commute. Finally, including road type as an interaction variable revealed the different effects on conflict likelihood that a given cycleway type can have, whether it is located on a local street, a collector street or an arterial road. Future research could evaluate the severity of the conflicts experienced by the cyclists and perform cross-analyses with collision and injury databases to further detail the relations between conflicts, collisions and safety.

Author Contributions: Conceptualization, V.J. and P.A.; methodology, data validation and statistical analyses, V.J. and P.A.; writing — original draft preparation, V.J. and P.A.; writing—review and editing, V.J. and P.A; supervision, project administration and funding acquisition: P.A. Both authors have read and agreed to the published version of the manuscript.

Funding: This study was financially supported by the Social Sciences and Humanities Research Council of Canada (SSHRC) through an Insight Grant (435-2019-0796) and through the Canada Graduate Scholarship—Master's program (first author).

Institutional Review Board Statement: This study has been approved by the Research Ethics Board of Institut national de la recherche scientifique (project No. CER 19-509, date of approval: 28 May 2019).

Informed Consent Statement: Informed consent was obtained from all subjects involved in the study.

Acknowledgments: Special thanks to the four courageous cyclists who were involved in the data collection, to Jérémy Gelb for his insights on statistical modeling, to Jennifer Ma-O for her support organizing the data collection and to Louis-Philippe Huard for his work in the video reviewing process.

Conflicts of Interest: The authors declare no conflict of interest.

\section{References}

1. Bassett, D.R.; Pucher, J.; Buehler, R.; Thompson, D.L.; Crouter, S.E. Walking, Cycling, and Obesity Rates in Europe, North America, and Australia. J. Phys. Act. Health 2008, 5, 795-814. [CrossRef]

2. Oja, P.; Titze, S.; Bauman, A.; De Geus, B.; Krenn, P.; Reger-Nash, B.; Kohlberger, T. Health benefits of cycling: A systematic review. Scand. J. Med. Sci. Sports 2011, 21, 496-509. [CrossRef] [PubMed]

3. Rojas-Rueda, D.; de Nazelle, A.; Tainio, M.; Nieuwenhuijsen, M.J. The health risks and benefits of cycling in urban environments compared with car use: Health impact assessment study. BMJ 2011, 343, d4521. [CrossRef]

4. Dons, E.; Rojas-Rueda, D.; Anaya-Boig, E.; Avila-Palencia, I.; Brand, C.; Cole-Hunter, T.; de Nazelle, A.; Eriksson, U.; GauppBerghausen, M.; Gerike, R.; et al. Transport mode choice and body mass index: Cross-sectional and longitudinal evidence from a European-wide study. Environ. Int. 2018, 119, 109-116. [CrossRef] [PubMed]

5. De Hartog, J.J.; Boogaard, H.; Nijland, H.; Hoek, G. Do the health benefits of cycling outweigh the risks? Environ. Health Perspect. 2010, 118, 1109-1116. [CrossRef]

6. Garrard, J.; Rissel, C.; Bauman, A. Health benefits of cycling. In City Cycling; Pucher, J., Buehler, R., Eds.; MIT Press: Cambridge, MA, USA, 2012.

7. Pucher, J.; Buehler, R.; Seinen, M. Bicycling renaissance in North America? An update and re-appraisal of cycling trends and policies. Transp. Res. Part A Policy Pract. 2011, 45, 451-475. [CrossRef]

8. Winters, M.; Davidson, G.; Kao, D.; Teschke, K. Motivators and deterrents of bicycling: Comparing influences on decisions to ride. Transportation 2011, 38, 153-168. [CrossRef]

9. Reynolds, C.C.O.; Harris, M.A.; Teschke, K.; Cripton, P.A.; Winters, M. The impact of transportation infrastructure on bicycling injuries and crashes: A review of the literature. Environ. Health 2009, 8, 47. [CrossRef] [PubMed]

10. Tin Tin, S.; Woodward, A.; Ameratunga, S. Completeness and accuracy of crash outcome data in a cohort of cyclists: A validation study. BMC Public Health 2013, 13, 420. [CrossRef]

11. Stipancic, J.; Zangenehpour, S.; Miranda-Moreno, L.; Saunier, N.; Granié, M.-A. Investigating the gender differences on bicyclevehicle conflicts at urban intersections using an ordered logit methodology. Accid. Anal. Prev. 2016, 97, 19-27. [CrossRef] 
12. Sener, I.N.; Eluru, N.; Bhat, C.R. An analysis of bicycle route choice preferences in Texas, US. Transportation 2009, 36, 511-539. [CrossRef]

13. Sanders, R.L. Perceived traffic risk for cyclists: The impact of near miss and collision experiences. Accid. Anal. Prev. 2015, 75, 26-34. [CrossRef] [PubMed]

14. Janeth, M.; Diana, C.P.; Luis Fernando, G.; Olga, S.; Tom, S.; Enrique, J. An Inside Look at Active Transportation in Bogotá: A Qualitative Study. J. Phys. Act. Health 2012, 9, 776-785. [CrossRef]

15. Van der Horst, A.R.A.; de Goede, M.; de Hair-Buijssen, S.; Methorst, R. Traffic conflicts on bicycle paths: A systematic observation of behaviour from video. Accid. Anal. Prev. 2014, 62, 358-368. [CrossRef]

16. Włodarek, P.; Olszewski, P. Traffic safety on cycle track crossings-traffic conflict technique. J. Transp. Safety Secur. 2019, 12, 194-209. [CrossRef]

17. Miranda-Moreno, L.F.; Strauss, J.; Morency, P. Disaggregate Exposure Measures and Injury Frequency Models of Cyclist Safety at Signalized Intersections. Transp. Res. Rec. 2011, 2236, 74-82. [CrossRef]

18. Dozza, M.; Werneke, J. Introducing naturalistic cycling data: What factors influence bicyclists' safety in the real world? Transp. Res. Part F Traffic Psychol. Behav. 2014, 24, 83-91. [CrossRef]

19. Petzoldt, T.; Schleinitz, K.; Heilmann, S.; Gehlert, T. Traffic conflicts and their contextual factors when riding conventional vs. electric bicycles. Transp. Res. Part F Traffic Psychol. Behav. 2017, 46, 477-490. [CrossRef]

20. Johnson, M.; Charlton, J.; Oxley, J.; Newstead, S. Naturalistic cycling study: Identifying risk factors for on-road commuter cyclists. Ann. Adv. Automot. Med. 2010, 54, 275-283.

21. Hamann, C.J.; Peek-Asa, C. Examination of adult and child bicyclist safety-relevant events using naturalistic bicycling methodology. Accid. Anal. Prev. 2017, 102, 1-11. [CrossRef]

22. Gustafsson, L.; Archer, J. A naturalistic study of commuter cyclists in the greater Stockholm area. Accid. Anal. Prev. 2013, 58, 286-298. [CrossRef] [PubMed]

23. Gadsby, A.; Watkins, K. Instrumented bikes and their use in studies on transportation behaviour, safety, and maintenance. Transp. Rev. 2020, 1-22. [CrossRef]

24. Vilaça, M.; Macedo, E.; Coelho, M.C. A Rare Event Modelling Approach to Assess Injury Severity Risk of Vulnerable Road Users. Safety 2019, 5, 29. [CrossRef]

25. Chen, P.; Shen, Q. Built environment effects on cyclist injury severity in automobile-involved bicycle crashes. Accid. Anal. Prev. 2016, 86, 239-246. [CrossRef] [PubMed]

26. Angel-Domenech, A.; García, A.; Agustin-Gomez, F.; Llorca, C. Traffic conflict analysis using an instrumented bicycle on cycle tracks of Valencia. In Proceedings of the International Cycling Safety Conference 2014, Göteborg, Sweden, 18-19 November 2014.

27. Carvajal, G.A.; Sarmiento, O.L.; Medaglia, A.L.; Cabrales, S.; Rodríguez, D.A.; Quistberg, D.A.; López, S. Bicycle safety in Bogotá: A seven-year analysis of bicyclists' collisions and fatalities. Accid. Anal. Prev. 2020, 144, 105596. [CrossRef]

28. Harris, M.A.; Reynolds, C.C.O.; Winters, M.; Cripton, P.A.; Shen, H.; Chipman, M.L.; Cusimano, M.D.; Babul, S.; Brubacher, J.R.; Friedman, S.M.; et al. Comparing the effects of infrastructure on bicycling injury at intersections and non-intersections using a case-crossover design. Inj. Prev. 2013, 19, 303-310. [CrossRef]

29. Jestico, B.; Nelson, T.A.; Potter, J.; Winters, M. Multiuse trail intersection safety analysis: A crowdsourced data perspective. Accid. Anal. Prev. 2017, 103, 65-71. [CrossRef]

30. Yiannakoulias, N.; Bennet, S.A.; Scott, D.M. Mapping commuter cycling risk in urban areas. Accid. Anal. Prev. 2012, 45, 164-172. [CrossRef]

31. Rahman, Z.; Mattingly, S.P.; Kawadgave, R.; Nostikasari, D.; Roeglin, N.; Casey, C.; Johnson, T. Using crowd sourcing to locate and characterize conflicts for vulnerable modes. Accid. Anal. Prev. 2019, 128, 32-39. [CrossRef]

32. Dozza, M.; González, N.P. Recognising safety critical events: Can automatic video processing improve naturalistic data analyses? Accid. Anal. Prev. 2013, 60, 298-304. [CrossRef]

33. Teschke, K.; Harris, M.A.; Reynolds, C.C.O.; Winters, M.; Babul, S.; Chipman, M.; Cusimano, M.D.; Brubacher, J.R.; Hunte, G.; Friedman, S.M.; et al. Route Infrastructure and the Risk of Injuries to Bicyclists: A Case-Crossover Study. Am. J. Public Health 2012, 102, 2336-2343. [CrossRef] [PubMed]

34. Lusk, A.C.; Furth, P.G.; Morency, P.; Miranda-Moreno, L.F.; Willett, W.C.; Dennerlein, J.T. Risk of injury for bicycling on cycle tracks versus in the street. Inj. Prev. 2011, 17, 131-135. [CrossRef]

35. Schleinitz, K.; Petzoldt, T.; Franke-Bartholdt, L.; Krems, J.F.; Gehlert, T. Conflict partners and infrastructure use in safety critical events in cycling-Results from a naturalistic cycling study. Transp. Res. Part F Traffic Psychol. Behav. 2015, 31, 99-111. [CrossRef]

36. Pucher, J.; Buehler, R. Cycling Trends and Policies in Canadian Cities. World Transp. Policy Pract. 2005, 11, 43-61. [CrossRef]

37. Furth, P.G. Bicycling infrastructure for mass cycling: A trans-Atlantic comparison. In City Cycling; MIT Press: Cambridge, MA, USA, 2012; pp. 105-140.

38. Vélo Québec. L'état du vélo à Montréal en 2015; Vélo Québec: Montréal, QC, Canada, 2015.

39. Harms, L.; Maarten, K. Cycling Facts; KiM Netherlands Institute for Transport Policy Analysis: Hague, Netherlands, 2018.

40. Houde, M.; Apparicio, P.; Séguin, A.-M. A ride for whom: Has cycling network expansion reduced inequities in accessibility in Montreal, Canada? J. Transp. Geogr. 2018, 68, 9-21. [CrossRef]

41. Fuller, D.; Gauvin, L.; Kestens, Y.; Daniel, M.; Fournier, M.; Morency, P.; Drouin, L. Impact Evaluation of a Public Bicycle Share Program on Cycling: A Case Example of BIXI in Montreal, Quebec. Am. J. Public Health 2013, 103, e85-e92. [CrossRef] 
42. Copenhagenize Design Co. The 2019 Index. Available online: https:/ / copenhagenizeindex.eu/ (accessed on 29 March 2021).

43. Gelb, J.; Apparicio, P. Cyclists' exposure to atmospheric and noise pollution: A systematic literature review. Transp. Rev. 2021, 1-24. [CrossRef]

44. Ville de Montréal. Réseau Cyclable. 2020. Available online: https://donnees.montreal.ca/ville-de-montreal/pistes-cyclables (accessed on 1 April 2021).

45. Ville de Montréal. Géobase-Réseau Routier. 2020. Available online: https://donnees.montreal.ca/ville-de-montreal/geobase (accessed on 1 April 2021).

46. Ministère des Transports. Classification Fonctionnelle; Gouvernement du Québec: Québec, QC, Canada, 2008.

47. Ministère de l'Énergie et des Ressources naturelles. Adresses Québec: Guide de L'utilisateur; Gouvernement du Québec: Québec, QC, Canada, 2019.

48. Apparicio, P.; Maignan, D.; Gelb, J. VIFECO: An Open-Source Software for Counting Features on a Video. J. Open Res. Softw. 2021, 9, 1-9. [CrossRef]

49. R Core Team. R: A Language and Environment for Statistical Computing; R Foundation for Statistical Computing: Vienna, Austria, 2020.

50. Wood, S.N. Fast stable restricted maximum likelihood and marginal likelihood estimation of semiparametric generalized linear models. J. R. Stat. Soc. Ser. B 2011, 73, 3-36. [CrossRef]

51. Werneke, J.; Dozza, M.; Karlsson, M. Safety-critical events in everyday cycling-Interviews with bicyclists and video annotation of safety-critical events in a naturalistic cycling study. Transp. Res. Part F Traffic Psychol. Behav. 2015, 35, 199-212. [CrossRef]

52. Beck, B.; Chong, D.; Olivier, J.; Perkins, M.; Tsay, A.; Rushford, A.; Li, L.; Cameron, P.; Fry, R.; Johnson, M. How much space do drivers provide when passing cyclists? Understanding the impact of motor vehicle and infrastructure characteristics on passing distance. Accid. Anal. Prev. 2019, 128, 253-260. [CrossRef] [PubMed]

53. Dill, J.; McNeil, N. Four types of cyclists? Examination of typology for better understanding of bicycling behavior and potential. Transp. Res. Rec. 2013, 2387, 129-138. [CrossRef]

54. Fortier, D.; Lesage, D.; Bégin, C. Les Aménagements Cyclables: Un Cadre Pour L'analyse Intégrée des Facteurs de Sécurité; Direction Développement des Individus et des Communautés, Institut national de santé publique du Québec: Québec, QC, Canada, 2009.

55. NACTO. Don't Give Up at the Intersection; National Association of City Transportation Officials: New York, NY, USA, 2019. 